\title{
Management of invasive cervical root resorption in a maxillary central incisor using Biodentine: A case report
}

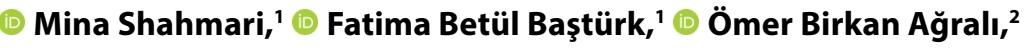 \\ D Hesna Sazak Öveçoğlu, ${ }^{1}$ 이 Bora Korkut ${ }^{3}$ \\ 'Department of Endodontics, Marmara University Faculty of Dentistry, Istanbul, Turkey \\ ${ }^{2}$ Department of Periodontics, Marmara University Faculty of Dentistry, Istanbul, Turkey \\ ${ }^{3}$ Department of Conservative Dentistry, Marmara University Faculty of Dentistry, Istanbul, Turkey
}

\begin{abstract}
Invasive cervical resorption (ICR) is a relatively uncommon form of external root resorption. The lesion is mainly detected on radiographs and exhibits no external signs. The radiographic appearance of ICR is an asymmetric radiolucent lesion with irregular margins and an unchanged root canal. Clinically, it usually begins on the cervical region of the root surface and may appear as asymptomatic pink discoloration of the tooth called "pink spot". The most commonly reported predisposing factors include traumatic dental injuries, orthodontic treatment, orthognathic surgery, periodontal diseases and treatments, and intracoronal bleaching. This paper reports the management of maxillary right central incisor diagnosed with external ICR using Biodentine with a multidisciplinary approach.
\end{abstract}

Keywords: Biodentine; external cervical resorption; invasive cervical resorption.

$\mathrm{R}$ oot resorption is a physiological process in primary teeth which results in exfoliation of the teeth, thereby allowing eruption of the permanent teeth. However, root resorption of permanent dentition is usually unfavorable due to damage and/or eventual tooth loss. ${ }^{[1]}$ Root resorption refers to the process of (ir)reversible destruction of cementum and dentin ${ }^{[2]}$ as a result of odontoclastic action. ${ }^{[3]}$ It might be classified as internal or external resorption according to its location in relation to the root surface. External cervical resorption (ECR) is an uncommon form of progressive external root resorption. Heithersay termed it as "invasive cervical resorption" which describes its invasive and aggressive nature. ${ }^{[4]}$

Clinically, cervical external resorption is related to inflammation of the periodontal tissues with no pulpal in- volvement. ${ }^{[5]}$ The pulp tissue in teeth with this resorption usually remains vital and remains protected by a thin layer of predentin until late in the process. ${ }^{[4,6]}$ ICR occurs at the cervical third of the root and can be misdiagnosed and confused with caries and internal resorptions. Often, affected tooth may show pinkish discoloration of tooth crown due to resorption of coronal dentin and enamel as highly vascular resorptive tissue becomes visible through this residual structure. ${ }^{[7]}$

ICRs are usually asymptomatic and are usually diagnosed during routine radiographic or clinical examination. ${ }^{[6,8]}$ Radiographic features of lesions vary from well-delineated to irregularly bordered mottled radiolucencies, and these can be confused with dental caries. ${ }^{[4]}$ A characteristic radiopaque line generally separates the image of the lesion

Correspondence: Dr. Mina Shahmari. Marmara Üniversitesi Diş Hekimliği Fakültesi,

Endodonti Anabilim Dalı, İstanbul, Turkey.

Tel: +90 531 - 5107477 e-mail: shahmar.m@gmail.com

Submitted: November 20, 2020 Accepted: November 28, 2020 
from that of the root canal, because the pulp remains protected by a thin layer of predentin until late in the process. ${ }^{[4]}$

The etiology of invasive cervical resorption is poorly understood. ${ }^{[9]}$ The most commonly reported predisposing factors include traumatic injuries, orthodontic tooth movement, orthognathic and dento-alveolar surgery, periodontal treatment, and internal bleaching. ${ }^{[7]}$

Heithersay G.S. has proposed a clinical classification of invasive cervical resorption depending on the amount of destruction: ${ }^{[4]}$

- Class 1: a small invasive resorptive lesion near the cervical area with shallow penetration into dentin

- Class 2: a well-defined invasive resorptive lesion that has penetrated close to the coronal pulp chamber but shows little or no extension into the radicular dentin

- Class 3: a deeper invasion of dentin by resorbing tissue, not only involving the coronal dentin but also extending into the coronal third of the root

- Class 4: a large, invasive resorptive process that has extended beyond the coronal third of the root.

Early diagnosis, complete removal of the resorptive defect and restorative management generally leads to a successful outcome in this cases. The cavity might be restored by appropriate restorative material like glass-inomer cement, composite resin, amalgam or calcium silicate-based cements such as $\mathrm{MTA}^{[10]}$ and Biodentine. ${ }^{[7]}$ Mineral trioxide aggregate (MTA) is a bioactive material and periodontal re-attachment can be expected on it. Biodentine can be a valid option since it acts as a substitute for dentin. ${ }^{[7]}$ It may combine acceptable aesthetics with the ability to support periodontal ligament (PDL) attachment. ${ }^{[2]}$ Therefore, the present case report was about describing surgical
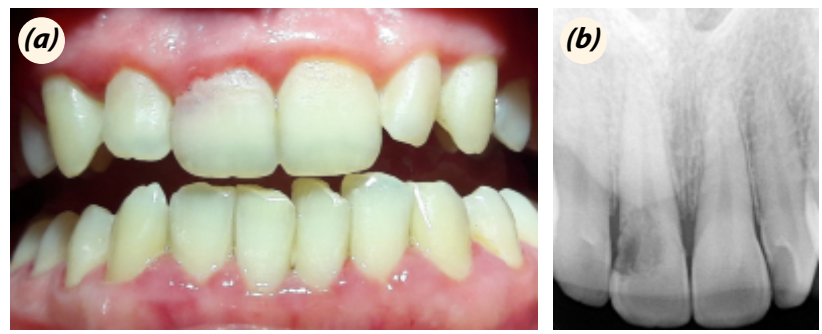

Fig. 1. (a) Preoperative intraoral photograph; (b) Preoperative periapical radiograph.
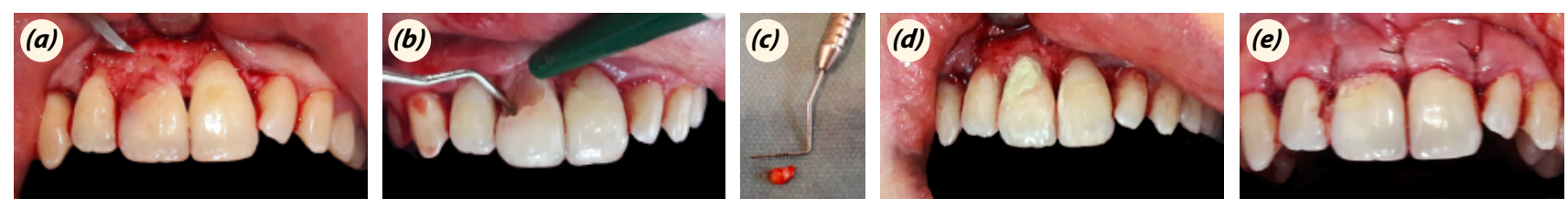

Fig. 2. (a) Cervical resorption defect seen after flap reflection; (b) Prepared cavity; (c)The granulomatous tissue; (d) Sealing the defect with Biodentine; management of maxillary right central incisor with external cervical resorption using Biodentine.

\section{Case report}

A 26-year-old female patient presented to the Endodontics Department, Dental School, Marmara University with a chief complaint of pinkish discoloration in upper right central incisor (Fig. la). Past dental history revealed that she had undergone trauma 3.5 years back and teeth remained untreated.

On clinical examination, the tooth was found to be vital due to the electric pulp test (EPT) and thermal test. Periodontal probing depths were physiological and no mobility was observed. Radiographic examination revealed an irregular, large radiolucent area in the cervical and distal aspect of 11 at supra-osseous level (Fig. 1b). The clinical diagnosis was external ICR.

As the defect was on the cervical area, a surgical intervention was planned for debridement, curettage, and restoration of the external resorption defect. Patient was then referred to department of Periodontics. Under local anesthesia, mucoperiosteal flap was raised. A large resorptive area was seen clearly from the surgical site containing granulation tissue (Fig. 2a). Granulomatous tissue was excavated from the resorptive area using hand excavator and no pulpal perforation was observed (Fig. 2b, c).

After debridement, the resorptive area was filled with Biodentine (Septodont, Saint-Maur-des-Fosses, France) and contoured as per external root anatomy (Fig. 2d). Finally, the flap was kept at its original position and sutured with absorbable suture material (Doğsan Pegelak ${ }^{\circledR}$, Trabzon, Türkiye) (Fig. 2e). The patient was reviewed 2 months later and a gingivectomy procedure was carried out.

Patient was then referred to department of Restorative Dentistry for direct esthetic resin composite restoration. The tooth was prepared minimally invasively under rubber-dam isolation. An anterior retraction clamp (212\# Black Line, Hu-Friedy, USA) was placed to retract gingival apically. A $45^{\circ}$ slight bevel was also prepared on labial surface to enhance the final esthteic outcome. Body shades (i.e., A2B and A3B) of Estelite Asteria (Tokuyama Dental, Tokyo, Japan), a supra-nano zirconia filler included resin-

\footnotetext{
Fig. 2. (a) Cervical resorption defect seen after flap reflection; (b) Prep
(e) Postperative intraoral photograph after flap repositioning.
} 
based composite, was used for the restoration. Free-hand was used as the layering technique with a composite brush and darker shade (A3B) was used more cervically to simulate the natural aesthetics (Fig. 3a). Finishing \& polishing procedure was performed using diamond-embeded spiral wheels (Twist Dia, Kuraray Noritake, Tokyo, Japan) (Fig. 3b-d).

Patient was recalled and reviewed at $1^{\text {st }}, 3^{\text {rd }}, 6^{\text {th }}, 12^{\text {th }}$ and $24^{\text {th }}$ month. She was completely asymptomatic and the tooth responded normally to EPT and thermal tests. The clinical and radiographic examinations indicated that repair of resorption defect was successfully treated with Biodentine (Fig. 4a, b).

\section{Discussion}

Root resorption of permanent dentition is pathological due to damage and/or eventual tooth loss. It might be classified as internal or external resorption. Cervical external root resorption or invasive cervical resorption is a localized resorptive process that commences on the surface of the root below the epithelial attachment and the coronal aspect of the supporting alveolar process. ${ }^{[11]}$ It can begin
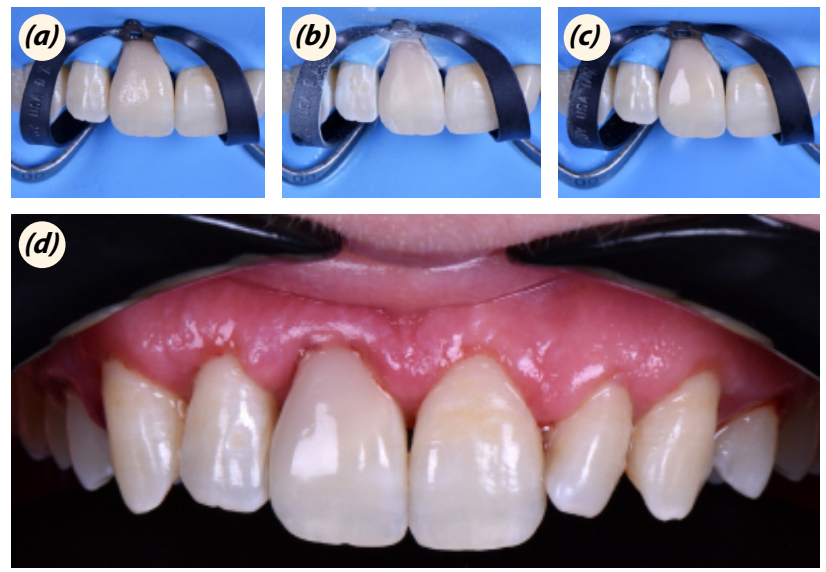

Fig. 3. (a-c) Restoration, finishing and polishing; (d) Postperative intraoral photograph after esthetic composite restoration.
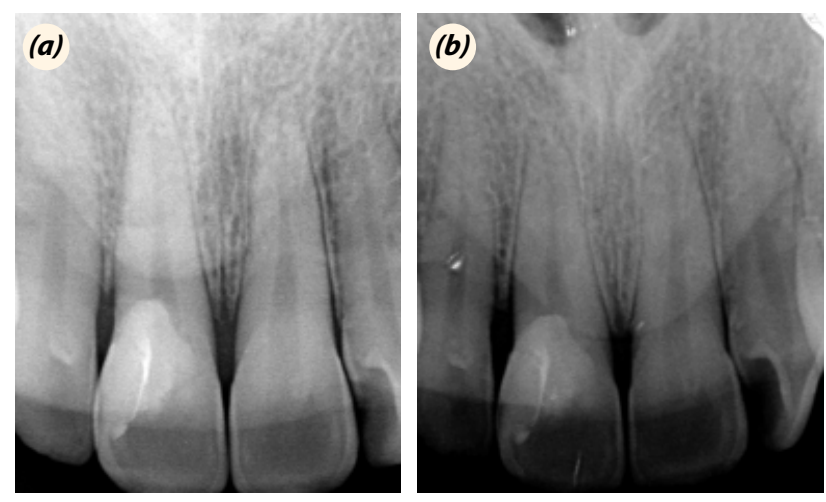

Fig. 4. (a) $6^{\text {th }}$ month follow-up radiograph; (b) $24^{\text {th }}$ months follow-up radiograph. and progress asymptomatically and is usually diagnosed during routine radiographic or clinical examination. It is sometimes difficult to distinguish this lesion from internal root resorption. So, CBCT may be extremely useful in the diagnoses of ICR. ${ }^{[12]}$ Early diagnosis is very important in the successful management of these patients.

The most common etiologic factors of ICR include traumatic injuries, orthodontic tooth movement, orthognathic and dento-alveolar surgery, periodontal treatment, and internal bleaching. ${ }^{[7]}$ The etiological factor in the present case seems to be traumatic injury.

Treatment of ICR depends on the severity, location, whether the defect has perforated the root canal system and the restorability of the tooth. ${ }^{[11]}$ The basic aim of treating is the complete removal of resorptive tissue and the restoration of the defect area. ${ }^{[2]}$ Surgical treatment of ICR generally involves periodontal flap reflection, curettage, granulation tissue removal, and restoration of the cavity by appropriate restorative material like glass-ionomer cement, ${ }^{[13]}$ calcium-enriched mixture (CEM) cement, ${ }^{[8,14]}$ calcium silicate-based cements such as $\mathrm{MTA}^{[15]}$ and Biodentine $^{[7]}$ and repositioning the flap to its original position. ${ }^{[16]}$ In the present case, no root canal treatment was performed as the tooth was vital due to the electric pulp and thermal test and no perforation of root canal was seen during surgical process. The resorptive defect was sealed with Biodentine using surgical intervention.

MTA has many favorable properties including a good sealing characteristic, biocompatibility, bactericidal effect, radiopacity, and ability to set up in the presence of blood. [17] Biodentine is another calcium silicate based cement using for endodontic treatments in the past recent years. It is a favorable repair material due to its bioactivity and biocompatibility. Biodentine has noticeably shorter setting time in contrast to other silicate cements such as MTA and also has better mechanical and handling properties. ${ }^{[18]}$ Its property to release calcium ion and enhancing the alkaline environment makes Biodentine more conducive for osteoblastic activity. ${ }^{[19,20]}$

The diagnosis for the present case was Heithersay's class III ICR. The treatment plan was surgical approach. Biodentine was selected to repair defect cavity due to its bioactivity, biocompatibility, better handling properties, faster setting time, less tooth discoloration, better sealing ability, less microleakage and better mechanical properties compared to other materials. After the treatment, the patient came for 3 and 6 month check-ups and did not follow the regular visits. She was completely asymptomatic, the radiographic examinations showed no signs of periapical pathology and the tooth responded normally to EPT and thermal tests. The clinical and radiographic examina- 
tions indicated that repair of resorption defect was successfully treated with Biodentine.

\section{Conclusion}

Early diagnosis, complete removal of the resorptive defect and an appropriate restorative management generally leads to a successful outcome and long-term retention of the tooth. Although this case report presents a favorable clinical outcome, further studies are necessary to provide more information about the use of Biodentine to fill external ICR defect.

Conflict of interest: None declared.

Authorship contributions: Concept: M.S., F.B.B., H.S.Ö.; Design: M.S., F.B.B., H.S.Ö.; Supervision: H.S.Ö.; Data: M.S., F.B.B., Ö.B.A., B.K.; Analysis: M.S., F.B.B.; Literature search: M.S.; Writing: M.S., Ö.B.A., B.K.; Critical revision: F.B.B.

\section{References}

1. Ahmed N, Gopalakrishnan, Mony B, Parthasarthy H. External cervical resorption case report and a brief review of literature. J Nat Sci Biol Med 2014;5:210-4.

2. Eftekhar L, Ashraf H, Jabbari S. Management of Invasive Cervical Root Resorption in a Mandibular Canine Using Biodentine as a Restorative Material: A Case Report. Iran Endod J 2017;12:386-89.

3. Patel S, Kanagasingam S, Pitt Ford T. External cervical resorption: a review. J Endod 2009;35:616-25.

4. Heithersay GS. Clinical, radiologic, and histopathologic features of invasive cervical resorption. Quintessence Int 1999;30:27-37.

5. Bergmans L, Van Cleynenbreugel J, Verbeken E, Wevers M, Van Meerbeek B, Lambrechts P. Cervical external root resorption in vital teeth. J Clin Periodontol 2002;29:580-5.

6. Frank AL, Torabinejad M. Diagnosis and treatment of extracanal invasive resorption. J Endod 1998;24:500-4.

7. Baranwal AK. Management of external invasive cervical resorption of tooth with Biodentine: A case report. J Conserv Dent 2016;19:296-9.

8. Asgary S, Nourzadeh M, Verma P, Hicks ML, Nosrat A.
Vital Pulp Therapy as a Conservative Approach for Management of Invasive Cervical Root Resorption: A Case Series. J Endod 2019;45:1161-67.

9. Ehlinger C, Ginies E, Bornert F, Bahi-Gross S, Schmittbuhl M, Minoux M. Decision criteria influencing the therapeutic approach to invasive cervical resorption: a case series. Quintessence Int 2019;50:494-502.

10. Kandalgaonkar SD, Gharat LA, Tupsakhare SD, Gabhane $\mathrm{MH}$. Invasive cervical resorption: a review. J Int Oral Health 2013;5:124-30.

11. Johns DA, Shivashankar VY, Maroli RK, Joseph R. Invasive cervical root resorption: Engineering the lost tissue by regeneration. Contemp Clin Dent 2013;4:536-9.

12. Vasconcelos Kde F, Nejaim Y, Haiter Neto F, Bóscolo FN. Diagnosis of invasive cervical resorption by using cone beam computed tomography: report of two cases. Braz Dent J 2012;23:602-7.

13. Tavares WL, Lopes RC, Oliveira RR, Souza RG, Henriques LC, Ribeiro-Sobrinho AP. Surgical management of invasive cervical resorption using resin-modified glass ionomer cement. Gen Dent 2013;61:e16-8.

14. Asgary S, Fazlyab M. Surgical repair of invasive cervical root resorption with calcium-enriched mixture cement: a case report. Gen Dent 2015;63:37-40.

15. Baratto-Filho F, Limongi O, Araújo Cde J, Neto MD, Maia SM, Santana D. Treatment of invasive cervical resorption with MTA: case report. Aust Endod J 2005;31:76-80.

16. Bansode PV, Pathak SD, Wavdhane MB, Birage PP. Root Resorption and It's Management: a Review Article. IOSR Journal of Dental and Medical Sciences (IOSR-JDMS), 2019:18:1;p. 63-9.

17. Yilmaz HG, Kalender A, Cengiz E. Use of mineral trioxide aggregate in the treatment of invasive cervical resorption: a case report. J Endod 2010;36:160-3.

18. Kaur M, Singh H, Dhillon JS, Batra M, Saini M. MTA versus Biodentine: Review of Literature with a Comparative Analysis. J Clin Diagn Res 2017;11:ZG01-05.

19. Rajasekharan S, Martens LC, Cauwels RG, Verbeeck RM. Biodentine $^{\mathrm{TM}}$ material characteristics and clinical applications: a review of the literature. Eur Arch Paediatr Dent 2014;15:147-58.

20. Priyalakshmi S, Ranjan M. Review on Biodentine-a bioactive dentin substitute. J Dent Med Sci 2014;13:p.51-7. 